\title{
Fatigue Notch Sensitivity of Some Aluminum Alloys
}

\author{
J. A. Bennett and J. G. Weinberg
}

\begin{abstract}
The notch sensitivity in fatigue was determined for $24 \mathrm{~S}-\mathrm{T} 4,61 \mathrm{~S}-\mathrm{T} 6$, and $75 \mathrm{~S}-\mathrm{T} 6$ aluminum alloys. Specimens having theoretical stress-concentration factors of 1.0, 1.4, and 1.8 were used, and the fatigue-strength reduction factor was based on the number of cycles required to initiate the fatigue crack. The values of notch sensitivity for $61 \mathrm{~S}-\mathrm{T} 6$ in the small radius specimens and for $24 \mathrm{~S}-\mathrm{T} 4$ were close to unity, whereas that for $75 \mathrm{~S}-\mathrm{T} 6$ was much lower. The data also provide information on the dispersion of fatigue results for the different alloys and the portion of the total life required for a fatigue crack to grow to fracture.
\end{abstract}

\section{Introduction}

The widespread use of aluminum alloys in aircraft has been due in large measure to the favorable strength-weight ratios of the high-strength alloys. However, as design stresses have increased, the problem of failure by fatigue has assumed continually greater importance. The problem has been studied extensively, and the literature dealing with the fatigue properties of aluminum alloys is voluminous [1]. ${ }^{1}$

Because fatigue failures in high-strength metals usually occur at stresses lower than those necessary for appreciable macroscopic plastic deformation, such failures will normally originate at points where the stress is concentrated by notches such as holes, grooves, scratches, or inhomogeneities in the metal. Consequently, the effect of notches on the fatigue strength of metals has been extensively studied, and several attempts have been made to predict the behavior of notched specimens from theoretical considerations $[2,3,4,5]$.

In studying the results of previous work on fatigue notch sensitivity, it was felt that two factors connected with the experimental work may have affected the results in such a way as to obscure the true effect of notches on fatigue properties. These factors were: (1) In many cases no attempt was made to make sure that the condition of the surface of the unnotched specimen was the same as that of the notched specimen at the point where the fatigue crack would be initiated. This was particularly true in tests with very sharply notched specimens. As the presence of a cold-worked layer is known to have a great effect on fatigue properties, any appreciable difference in the degree of cold-work between the two types of specimen would be expected to affect the apparent notch sensitivity. (2) The life of a fatigue-test specimen is made up of two periods; that in which no visible change occurs but which culminates in the formation of a small crack, and that in which the crack grows until fracture takes place. In smooth specimens the second stage is usually only a small part of the total life, so that no serious error is involved in ignoring it. However, as shown in previous work [10], the second stage may constitute 50 percent of the life of mildly notched specimens, and cannot be

${ }_{1}^{1}$ Figures in brackets indicate the literature references at the end of this paper. neglected. The factors that control the rate of growth of fatigue cracks are quite different from those governing the first stage. Therefore, if both stages are taken together, as in a test run to fracture, there is little hope of obtaining agreement with theoretical considerations.

With these considerations in mind, experimental work was undertaken to evaluate the fatigue notch sensitivity of three aluminum alloys. The following report gives the results and a discussion of these experiments.

The symbols used in this report are largely the same as those listed in reference [7], namely, $S_{a}$, stress amplitude; $N$, fatigue life $\left(N_{c}\right.$ denotes the number of cycles to the initiation of the first crack, $N_{f}$ the number of cycles to fracture); $K_{t}$, stress concentration factor; $K_{f}$, fatigue strength reduction factor; and $q$, notch sensitivity, equals $\left(K_{f}-1\right) /$ $\left(K_{t}-1\right)$.

\section{Materials and Test Methods}

The three materials, 24S-T4, $61 \mathrm{~S}$ T6, and $75 \mathrm{~S}-\mathrm{T} 6$, were obtained in the form of $1 / 2$-in. diam rod treated commercially. No further heat treatment was given any of the alloys. The composition of each of the alloys, determined by spectrochemical analysis (table 1), was within the specification limits. The static mechanical properties listed in table 2 are also within the ranges typically found in these alloys.

Metallographic examinations showed the three materials to be normal in regard to grain size and microstructure, except that the $75 \mathrm{~S}$ contained a large number of oversized particles of insoluble constituent believed to be the chromium-bearing constituent referred to in reference [8]. Particles as large as that shown in figure 1 were not unusual, and this is considerably larger than the example referred to as oversize in reference [8].

Fatigue tests were made on R. R. Moore rotatingbeam machines usually operated at 5,000 to 7,000 $\mathrm{rpm}$. The three types of specimens used are shown in figure 2. Fillets were used rather than grooves for stress raisers in order to permit better illumination of the surface where the fatigue crack would start. The theoretical stress-concentration factors, as determined from the curves in reference [5], were 1.40 and 1.79 for the $1 / 16^{-i n}$. and 0.025 -in. radius fillets, respectively. 


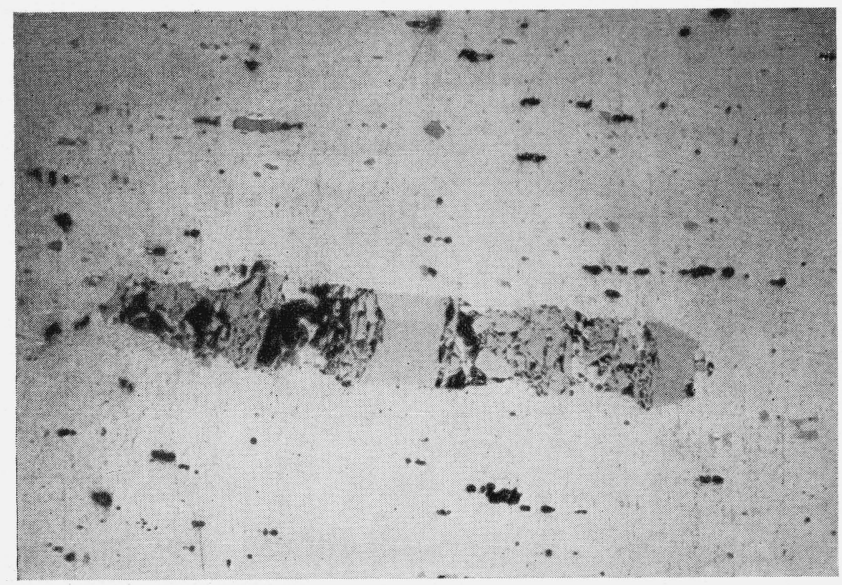

Figure 1. Large particle of segregated phase in 75S-T6.

Particles of this size were not unusual in the material tested. Unetched, $\times 200$.

TABLE 1. Spectrochemical analyses of alloys tested

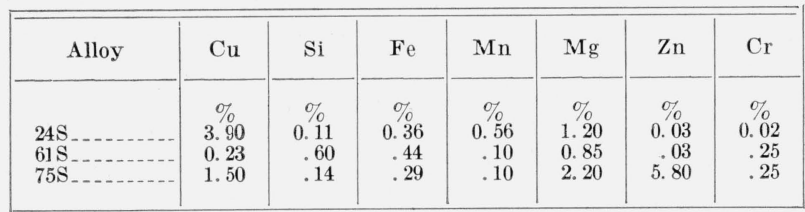

Because of previous difficulty with hand polishing of unnotched fatigue specimens, a machine was developed to do this operation automatically. As shown in figure 3, it consists of three parts: a wheel carrying an abrasive belt, a means for supporting and rotating the specimen during the polishing operation, and a means for moving the specimen across the belt during polishing. The wheel consists of a number of thin spring leaves, radiating from a hub, which press against the belt. This causes the belt to conform to the contour of the specimen and assures a small uniform pressure between the specimen and the abrasive. The specimen rotates 1 revolution for 40 revolutions of the wheel, and is simultaneously moved across the belt by means of a drive nut and cord arrangement. This assures that fresh abrasive is being used at all times and reduces the possibility of a burnishing action. With the wheel rotating at $180 \mathrm{rpm}$, the specimen moves across the belt in about $1 \mathrm{~min}$, and this was usually sufficient to eliminate previous machining marks, using 600 Aloxite paper as the abrasive. No attempt was made to obtain a highly polished surface, but the above procedure appeared to give very uniform results from specimen to specimen.

The filleted specimens were polished in the conventional manner with a rotating wire, over which was carried 302 emery suspended in a mixture of glycerine and water. The polishing wire was supported in a pivoted jig to assure uniform pressure.

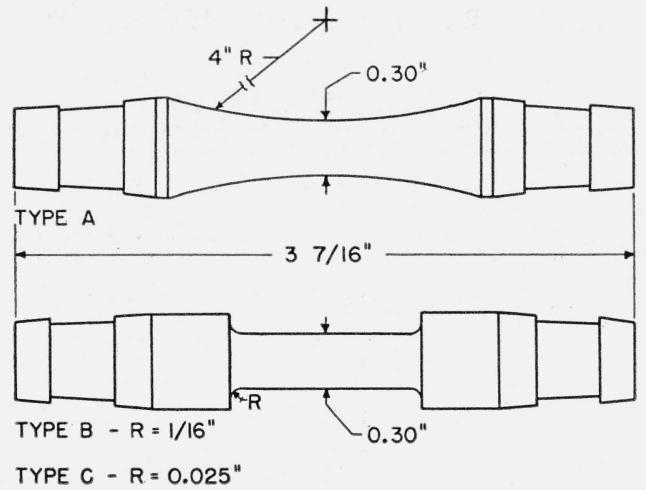

FIGURE 2. The three types of specimens used in the investigation.

TABLE 2. Mechanical properties of specimens

\begin{tabular}{|c|c|c|c|c|}
\hline Alloy & $\begin{array}{l}\text { Tensile } \\
\text { strength }\end{array}$ & $\begin{array}{c}\text { Yield s } \\
\text { strength }\end{array}$ & $\begin{array}{l}\text { Elongation } \\
\quad 2 \text { in. }\end{array}$ & $\begin{array}{l}\text { Brinell hard-- } \\
\text { ness number } \\
\text { (500 kg; } \\
10-\mathrm{mm} \text { ball) }\end{array}$ \\
\hline $\begin{array}{l}24 \mathrm{~S}-\mathrm{T} 4 \\
61 \mathrm{~S}-\mathrm{T} 6\end{array}$ & $\begin{array}{l}\text { lb/in. } .^{2}, 500 \\
48,000\end{array}$ & $\begin{array}{l}l b / \text { in. } .^{2} \\
56,500 \\
40,000\end{array}$ & $\begin{array}{r}\% \\
17.8 \\
21.0\end{array}$ & $\begin{array}{r}126 \\
94\end{array}$ \\
\hline $75 \mathrm{~S}-\mathrm{T} 6$ & 84,500 & 73,500 & 16.4 & 151 \\
\hline
\end{tabular}

s 0.2 -percent offset.

Figure 4 shows a comparison of the surfaces of the unnotched and 1/16-in.-radius fillet specimens. All specimens were carefully examined to make sure that all circumferential tool marks and scratches had been removed before testing.

The minimum diameter of each specimen was measured at four positions around the circumference on a toolmaker's microscope at 30 magnification. Specimens having a variation of more than 0.0002 in. in diameter were discarded. The fillet radii of the stress-concentration specimens were checked at the same time that the diameter was measured.

The determination of the number of cycles at which a fatigue crack starts is a difficult and somewhat uncertain procedure; it is obvious that accuracy of the determination will depend primarily on the minimum size of crack it is possible to detect. In previous investigations at the Bureau small cracks have been detected by (1) measurement of the increased deflection under the test load [9], (2) observation of the specimen under stroboscopic light [6], and (3) the use of fracture wires [10].

Three methods of crack detection were used in the present investigation. The first was a deflection method similar to (1) above, except that the contact was mounted on a lever attached to one bearing box. When the machine had run long enough to reach temperature equilibrium the contact was advanced to a position just short of touching a fixed plate. Any increase of deflection then caused contact with 


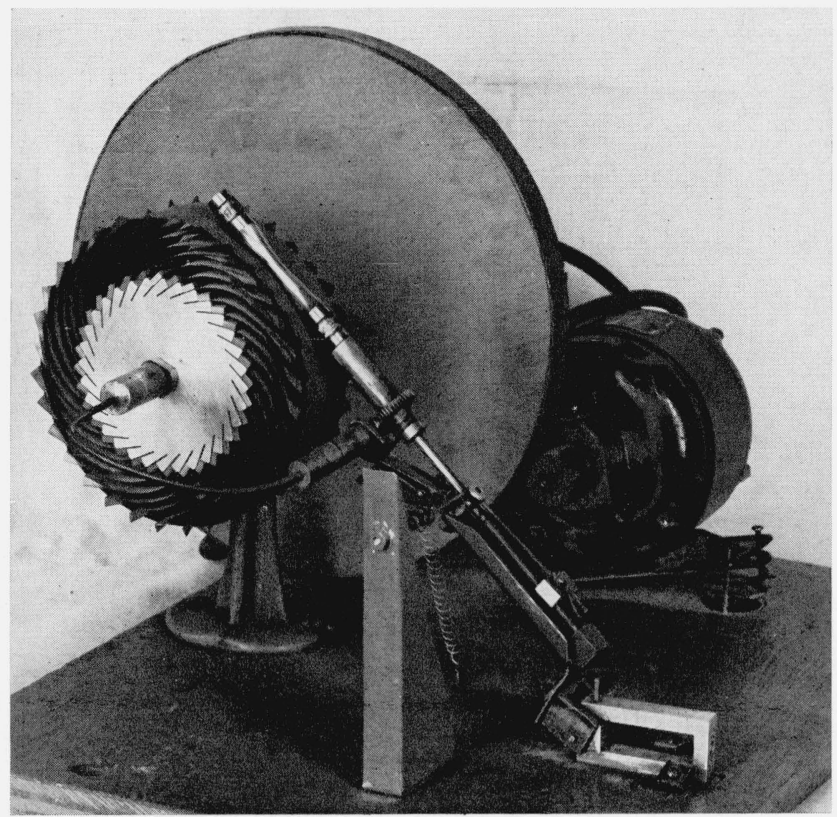

FiguRE 3. Apparatus used for polishing unnotched fatigue test specimens.

The polishing wheel, consisting of a number of metal spring leaves, presses an abrasive belt against the specimen with uniform pressure. The specimen rotate at a constant rate and advances slowly over the abrasive surface.

the plate, which operated an electronic relay to shut off the machine.

The second was a vibration-responsive method, which depended for its operation on the fact that a cracked specimen will deflect more when the crack is on the tension side than when it is on the compression side. This condition results in increased vibration of the specimen bearing-box assembly. Two vibration-sensitive devices were used to stop the machine; the first consists of a three-pronged pedestal on which a steel ball is balanced. The second, shown in figure 5, is similar, except that the pedestal is horizontal and the ball is held on the pedestal by the magnetic field of a small permanent magnet. In both devices the increased vibration caused by a crack shakes the ball from the pedestal; the ball drops between metal plates, completing a circuit that shuts off the machine. The second device was somewhat more useful than the first because the force holding the ball onto the pedestal could be varied by an adjustable soft-iron shunt across the poles of the permanent magnet.

The effectiveness of either the deflection method or the vibration method was closely associated with the degree of vibration present at the beginning of the test. When this was sufficient to be felt by touching the bearing box, there was little chance of detecting a small crack.

The third method of crack detection was merely that of inspecting the specimen at intervals during the part of the test when there was a chance of the crack developing. Often this method was combined with one of the other two by setting the automatic

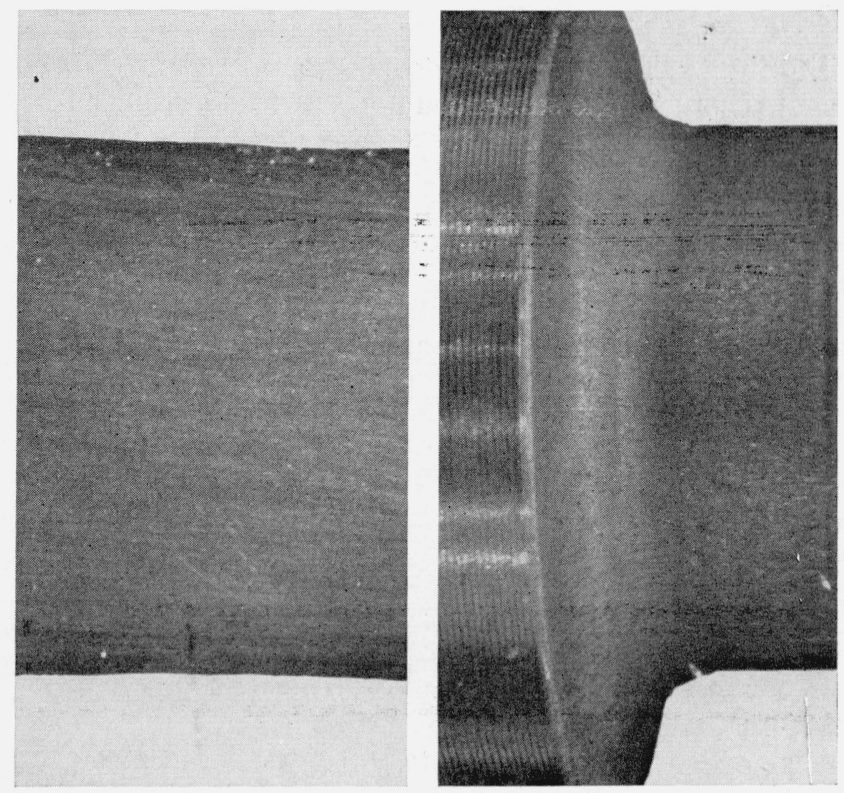

Figure 4. Comparison of the surface finish on an unnotched specimen with that on a 1/16-inch-radius filleted specimen.

$$
\times 7 \text {. }
$$

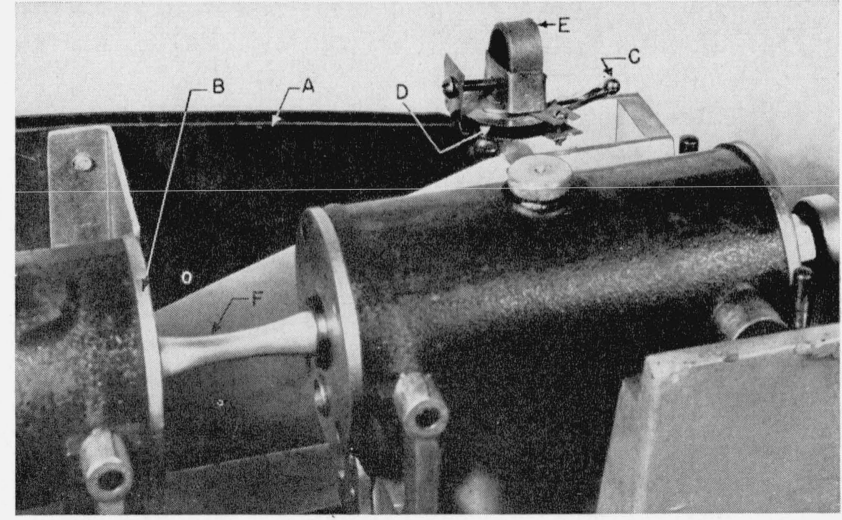

Figure 5. Vibration-responsive stopping device.

At the end of a 12-inch lever (A) fastened to bearing box (B) a small steel ball (C) is delicately balanced on three prongs by means of a magnetic field created by a small permanent magnet (D). An adjustable "keeper" (E) controls the strength of the magnetic field that holds the steel ball in place. Vibration caused sy the formation of a crack in specimen $(\mathrm{F})$ causes the steel ball to drop which closes an electrical circuit stopping the machine.

device so closely that numerous "false alarms" occurred. By inspecting the specimen each time the device tripped, the probability of finding a small crack was increased, but there was still a large element of chance involved.

For inspection, the specimen and bearing boxes were removed from the machine and supported in an inverted position on the loading-point knife-edge seats. Small weights were applied to the ends of the bearing boxes to put the upper surface of the specimen in tension, and the examination was made with a binocular microscope. A small fluorescent 
amp was found to give the most satisfactory illumination for the detection of small cracks. The central angle subtended by a crack was measured by means of a divided drum fitted on one of the bearingbox spindles, the ends of the crack being located by means of cross hairs in one eyepiece.

When a crack was found, its growth was followed by measurements after appropriate periods of stressing, and an attempt was made to determine by extrapolation the number of cycles at which the crack started. Although the variation in the rate of erack growth at a given stress was considerably less than that in the first stage of the test, it appeared that reasonable accuracy of extrapolation could be obtained only if the crack had been first observed when its length was less than 10 percent of the circumference. This requirement was considerably more difficult to fulfill with the notched specimens than with the smooth ones, because the cracks were much shallower in proportion to their length and were therefore more difficult to observe.

In order to make sure that the periodic stopping of the tests did not affect the results, many of the tests were run without interruption, but in these tests the crack usually extended over more than 10 percent of the circumference when detected. At each stress level an attempt was made to obtain two or more reliable curves of crack growth; the $N_{c}$ values for the uninterrupted tests were obtained by extrapolation based on the most reliable crackgrowth curves for that stress level.

The uncertainty inherent in the determination of $N_{c}$ was minimized in two ways. First, in tests that were interrupted periodically there were numerous instances when the origin of the crack was bracketed rather closely by two consecutive inspections, the first of which did not disclose any crack, and the second of which did. Second, the ratio of $N_{c}$ to $N_{f}$ was a fairly reproducible function of the stress amplitude for a given specimen type and material. These relationships, shown in figure 6 for the 24S-T4 specimens, provided a means of comparing the data obtained at different stress levels and assisted in determining when crack-growth data of sufficient accuracy had been obtained. The accuracy of the measurement of small cracks was verified on a few specimens by removing them from the fatigue machine after the first observation of the crack. The specimens were then extended under axial tension, which made the extent of the crack clearly discernible.

\section{Results and Discussion}

It was originally planned to determine the notch sensitivity over a range from about $5 \times 10^{4}$ to $5 \times 10^{7}$ cycles. On the basis of some preliminary tests, five stress levels were chosen for the tests on each alloy. Howevar, as the experimental work progressed it was found that the dispersion of the data for the 75S-T6 unnotched specimens was so large at the lowest stress level that it was not possible to obtain significant results with a reasonable number of

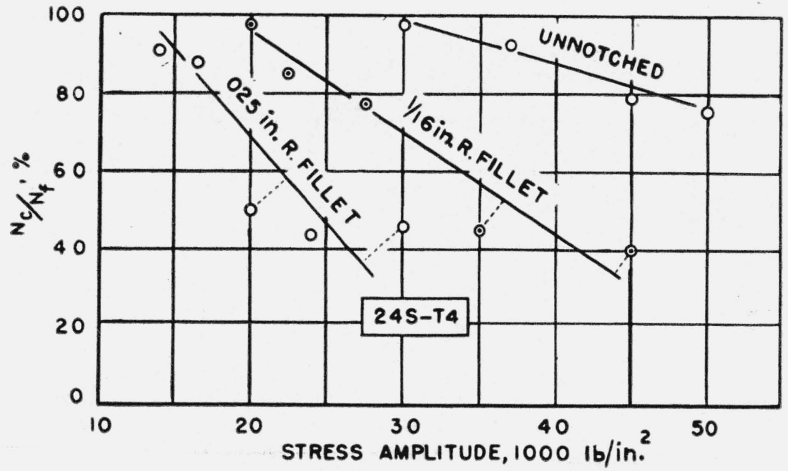

FIGURE 6. Effect of stress amplitude on the proportion of the total life required to initiate a crack in $24 S-T 4$ specimens.

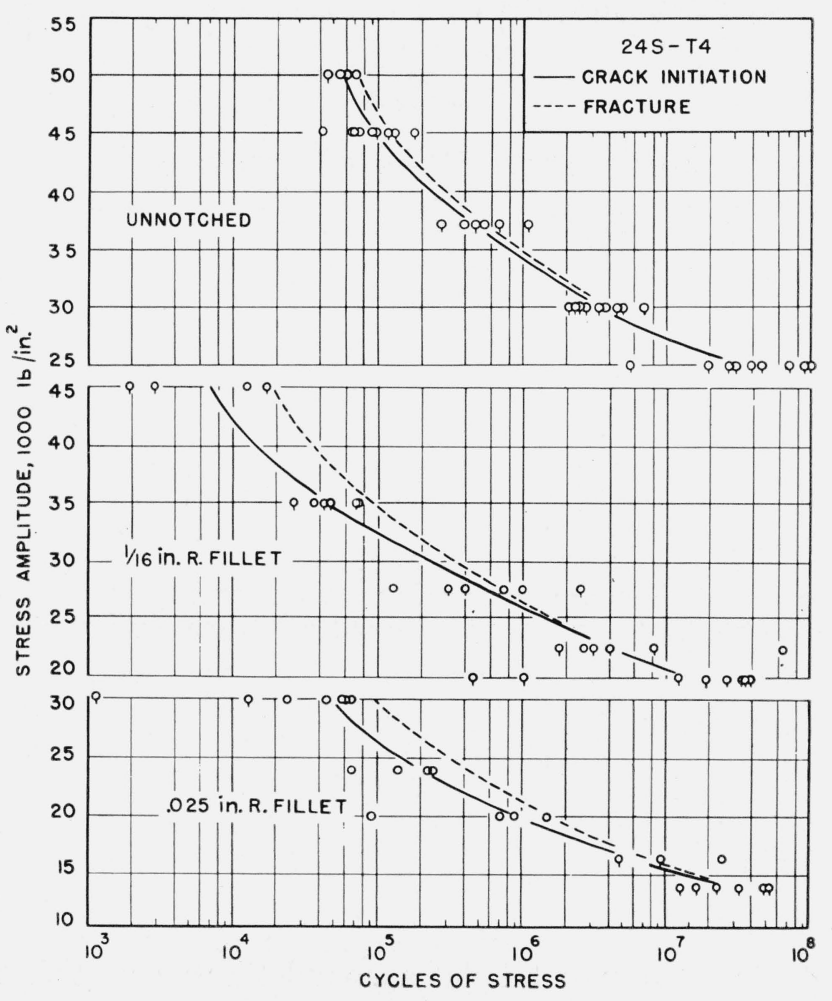

Figure 7. S-N curves for 24S-T4 specimens.

The data points and the solid curves represent the number of cycles for crack initiation. A short vertical line below a point indicates that the value of $N_{0}$ was obtained from $N_{f}$ by using crack-growth data from other specimens.

specimens. Accordingly, the data for this alloy do not go beyond about $10^{6}$ cycles.

Figures 7, 8, and 9 show the $N_{c}$ data for the three alloys. The trend of the data for the number of cycles to fracture is shown by the dashed lines. The short vertical lines below some of the data points indicate that the cracks in these specimens were relatively large when first observed, or that the specimen was run to fracture without stopping, so that the $N_{c}$ values plotted were obtained by extra- 


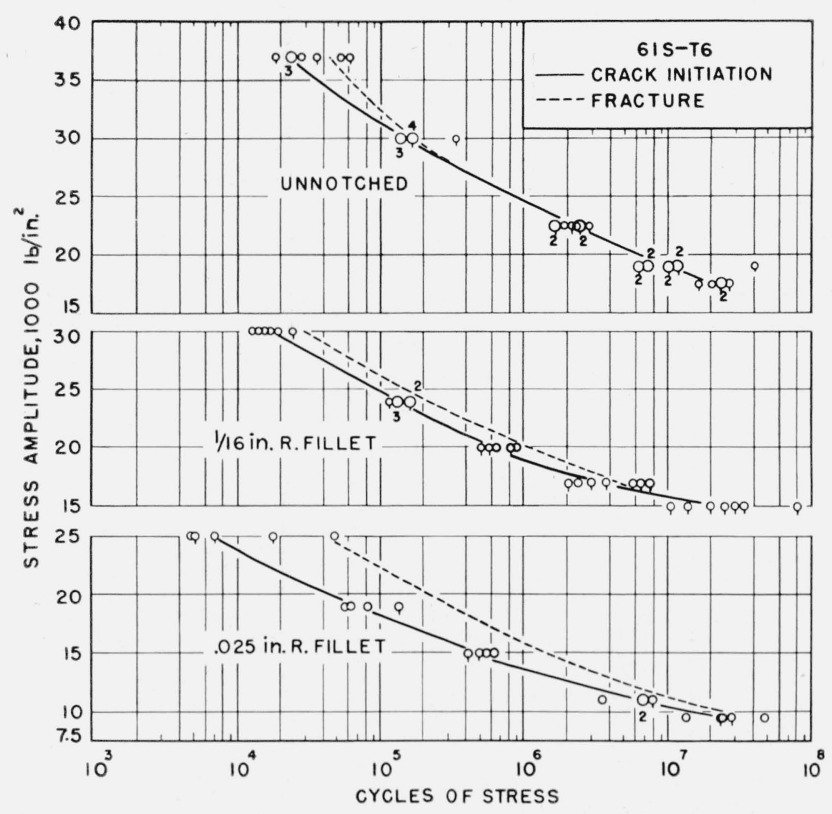

Figure 8. S-N curves for $61 S-T 6$ specimens.

See figure 7 for explanation of symbols.

polation, using other crack-growth data. The number of cycles for fracture of each specimen is listed in table 3 . The number of specimens listed in this table at each stress level does not correspond in all cases to the points on the graphs of figures 7 to 9 because of the specimens mentioned above, which were removed from the fatigue machine after the first observation of the crack and extended under static load. These specimens are represented by a point on the graph, but no fracture value is available.

In tests of the type B (1/16-in.-radius fillet) specimens of 75S-T6, some difficulty was experienced with specimens breaking in the straight section rather than at the fillet. This was not eliminated by careful smoothing of the straight section. If a crack was found in the fillet after this type of fracture, the extrapolated value of $N_{c}$ was obtained in the usual way. If no crack was found in either fillet, it was obvious that $N_{c}$ for that specimen had not been attained. Data from these specimens could be used in determining the median if the number of cycles actually run was larger than the median, otherwise they had to be disregarded. Data of this type that were used are indicated in figure 9 by the conventional symbol for a specimen that did not break. All fractures occurred in the fillets in both of the other alloys.

The median $N_{c}$ values are plotted in figures 10 , 11 , and 12 in the manner suggested in reference [10]. In some cases the data plotted in this way lie more nearly on a straight line than in the conventional plot, thus facilitating interpolation. In other cases there is no advantage, but for the sake of consistency,

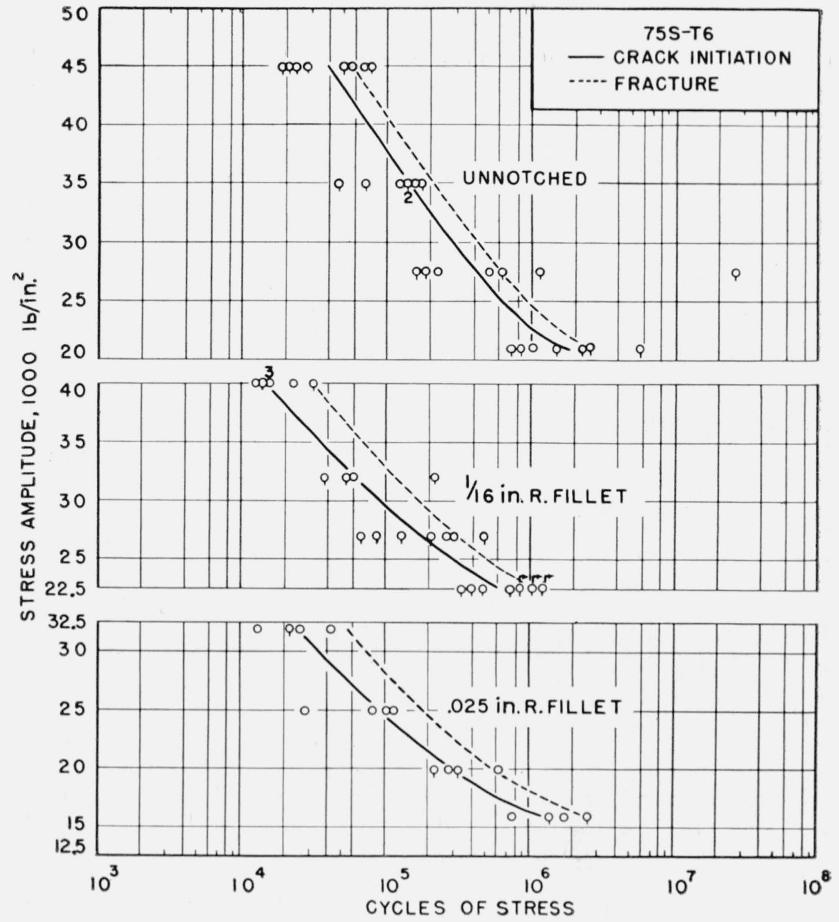

Figure 9. S-N curves for 75S-T6 specimens.

See figure 7 for explanation of symbols.

all determinations of notch sensitivity were based on the curves of figures 10 to 12 .

The fatigue-strength reduction factors for the two types of specimens of each of the three alloys are shown in figure 13 . The notch sensitivity, g, was computed by using these data and values of theoretical stress-concentration factor obtained from the graphs of reference [5]. These data are listed in table 4 and shown in figure 14 .

Because of the widespread current interest in the statistical characteristics of fatigue data [11], consideration was given to the significance of the dispersion of results presented here. It should be pointed out that the measurement of $N_{c}$, unlike that of $N_{f}$, is not precise for a given specimen. As there was no way to separate the error of measurement from the inherent variability from specimen to specimen, it was not thought worthwhile to make any extensive quantitative analysis of the dispersion of $N_{c}$.

However, it was thought that a reasonable comparison between the three materials could be obtained by considering the data for unnotched specimens at all stress levels. This was done by comparing each value of $N_{c}$ with the median for that stress level. The results were as follows:

24S-T4: $50 \%$ of the data were within $34 \%$ of the median $N_{\text {e }}$ values.

61S-T6: $50 \%$ of the data were within $12 \%$ of the median $N_{0}$ values.

75S-T6: $50 \%$ of the data were within $76 \%$ cf the median $N_{\mathrm{e}}$ values. 
TABLE 3. Results of fatigue tests

\begin{tabular}{|c|c|c|c|c|c|}
\hline \multicolumn{2}{|c|}{ Unnotched } & \multicolumn{2}{|c|}{$\begin{array}{l}\text { 1/16-in.-radius } \\
\text { specimen }\end{array}$} & \multicolumn{2}{|c|}{$\begin{array}{l}\text { 0.025-in.-radius } \\
\text { specimen }\end{array}$} \\
\hline $\begin{array}{l}\text { Stress } \\
\text { ampli- } \\
\text { tude }\end{array}$ & $\begin{array}{l}\text { Cycles to } \\
\text { fracture }\end{array}$ & $\begin{array}{l}\text { Stress } \\
\text { ampli- } \\
\text { tude }\end{array}$ & $\begin{array}{l}\text { Cycles to } \\
\text { fracture }\end{array}$ & $\begin{array}{l}\text { Stress } \\
\text { ampli- } \\
\text { tude }\end{array}$ & $\begin{array}{l}\text { Cycles to } \\
\text { fracture }\end{array}$ \\
\hline \multicolumn{6}{|c|}{ 24S-T4 SPECIMENS } \\
\hline $\begin{array}{l}l b / \text { in }^{2} \\
50,000\end{array}$ & $\left\{\begin{array}{c}90 \times 10^{3} \\
75 \\
75 \\
65 \\
61 \\
121 \\
144 \\
150 \\
103 \\
103 \\
91 \\
162 \\
215 \\
1,209 \\
516 \\
730 \\
521 \\
551 \\
446 \\
3,052 \\
7,405 \\
4,900 \\
3,714 \\
4,105 \\
2,677 \\
2,301 \\
5,206 \\
2,621 \\
\{101,622 \\
6,000 \\
76,395 \\
39,832 \\
49,328 \\
42,978 \\
29,139 \\
98,382 \\
22,024\end{array}\right.$ & $\begin{array}{l}l b / \text { in }^{2} \\
45,000 \\
35,000\end{array}$ & $\begin{array}{c}14 \times 10^{3} \\
31 \\
15 \\
25 \\
133 \\
115 \\
82 \\
98 \\
98 \\
90 \\
2,812 \\
1,194 \\
513 \\
906 \\
532 \\
490 \\
2,563 \\
3,445 \\
5,047 \\
70,964 \\
9,381 \\
3,919 \\
29,865 \\
39,624 \\
38,223 \\
43,721 \\
1,763 \\
13,774 \\
988 \\
21,566\end{array}$ & $\begin{array}{l}l b / \text { in }^{2} \\
30,000 \\
24,000 \\
20,000 \\
16,500 \\
14,000\end{array}$ & $\begin{array}{c}73 \times 10^{3} \\
105 \\
91 \\
125 \\
490 \\
308 \\
485 \\
419 \\
1,659 \\
1,677 \\
782 \\
2,571 \\
6,607 \\
11,860 \\
31,957 \\
19,618 \\
16,306 \\
58,059 \\
39,774 \\
59,049 \\
20,812\end{array}$ \\
\hline \multicolumn{6}{|c|}{ 61S-T6 SPECIMENS } \\
\hline 30,000 & $\begin{array}{c}69 \times 10^{3} \\
76 \\
51 \\
43 \\
37 \\
36 \\
47 \\
34 \\
163 \\
187 \\
352 \\
156 \\
186 \\
174 \\
176 \\
163 \\
2,979 \\
2,482 \\
2,205 \\
2,762 \\
2,838 \\
2,803 \\
2,038 \\
2,050 \\
11,669 \\
12,181 \\
51,145 \\
11,955 \\
7,492 \\
11,053 \\
7,322 \\
7,820 \\
7,714 \\
27,635 \\
24,127 \\
27,042 \\
20,101 \\
24,597\end{array}$ & 17.000 & $\begin{array}{c}37 \times 10^{3} \\
29 \\
30 \\
32 \\
27 \\
39 \\
223 \\
231 \\
190 \\
197 \\
230 \\
183 \\
1,349 \\
1,017 \\
1,031 \\
1,212 \\
1,351 \\
8,342 \\
4,712 \\
3,462 \\
2,996 \\
3,882 \\
6,548 \\
7,291 \\
35,806 \\
27,333 \\
82,428 \\
31,269 \\
21,852 \\
12,337 \\
16.096\end{array}$ & $\begin{array}{l}25.000 \\
19,000 \\
15,000 \\
11,000\end{array}$ & $\begin{array}{c}74 \times 10^{3} \\
53 \\
33 \\
31 \\
393 \\
372 \\
316 \\
194 \\
1,452 \\
1,419 \\
946 \\
1,543 \\
14,176 \\
11,844 \\
16,617 \\
9,986 \\
42,806 \\
27,743 \\
37,783 \\
54,412\end{array}$ \\
\hline
\end{tabular}

TABLE 3. Results of fatigue tests-Continued

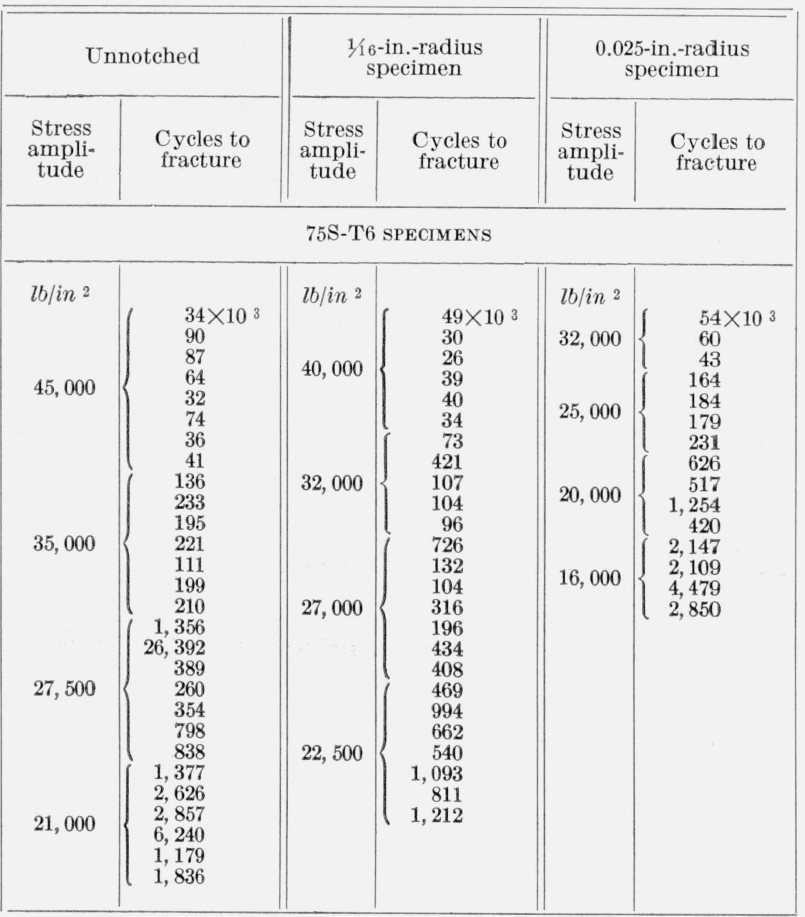

TABLE 4. Strength-reduction factors and values of notch sensitivity

\begin{tabular}{|c|c|c|c|c|}
\hline \multirow{2}{*}{ Cycles } & \multicolumn{2}{|c|}{$K_{f}$} & \multicolumn{2}{|c|}{$q=\left(K_{f}-1\right) /\left(K_{t}-1\right)$} \\
\hline & $K_{t}=1.40$ & $K_{t}=1.79$ & $K_{t}=1.40$ & $K_{t}=1.79$ \\
\hline \multicolumn{5}{|c|}{$24 \mathrm{~S}-\mathrm{T} 4$} \\
\hline $\begin{array}{c}50 \times 10^{3} \\
100 \\
500 \\
1,000 \\
5,000 \\
10,000 \\
20,000\end{array}$ & $\begin{array}{l}1.43 \\
1.41 \\
1.37 \\
1.34 \\
1.32 \\
1.31 \\
1.30\end{array}$ & $\begin{array}{l}\text { 1. } 73 \\
\text { 1. } 72 \\
\text { 1. } 74 \\
\text { 1. } 74 \\
\text { 1. } 74 \\
\text { 1. } 74 \\
\text { 1. } 74\end{array}$ & $\begin{array}{r}1.07 \\
1.02 \\
0.93 \\
.87 \\
.82 \\
.79 \\
.75\end{array}$ & $\begin{array}{r}0.92 \\
.92 \\
.91 \\
.94 \\
.94 \\
.94 \\
.94\end{array}$ \\
\hline \multicolumn{5}{|c|}{ 61S-T6 } \\
\hline $\begin{array}{c}50 \times 10^{3} \\
100 \\
500 \\
1,000 \\
5,000 \\
10,000 \\
20,000\end{array}$ & $\begin{array}{l}1.27 \\
1.28 \\
1.27 \\
1.27 \\
1.22 \\
1.19 \\
1.15\end{array}$ & $\begin{array}{l}1.72 \\
1.71 \\
1.72 \\
1.75 \\
1.79 \\
1.79 \\
1.80\end{array}$ & $\begin{array}{r}0.68 \\
.70 \\
.68 \\
.68 \\
.58 \\
.48 \\
.38\end{array}$ & $\begin{array}{r}0.91 \\
.90 \\
.91 \\
.95 \\
1.00 \\
1.00 \\
1.01\end{array}$ \\
\hline \multicolumn{5}{|c|}{$75 \mathrm{~S}-\mathrm{T} 6$} \\
\hline $\begin{array}{c}50 \times 10^{3} \\
100 \\
500 \\
1,000\end{array}$ & $\begin{array}{l}1.29 \\
1.26 \\
1.18 \\
1.12\end{array}$ & $\begin{array}{l}1.53 \\
1.51 \\
\text { 1. } 47 \\
1.41\end{array}$ & $\begin{array}{r}0.73 \\
.65 \\
.45 \\
.30\end{array}$ & $\begin{array}{r}0.67 \\
.65 \\
.60 \\
.52\end{array}$ \\
\hline
\end{tabular}




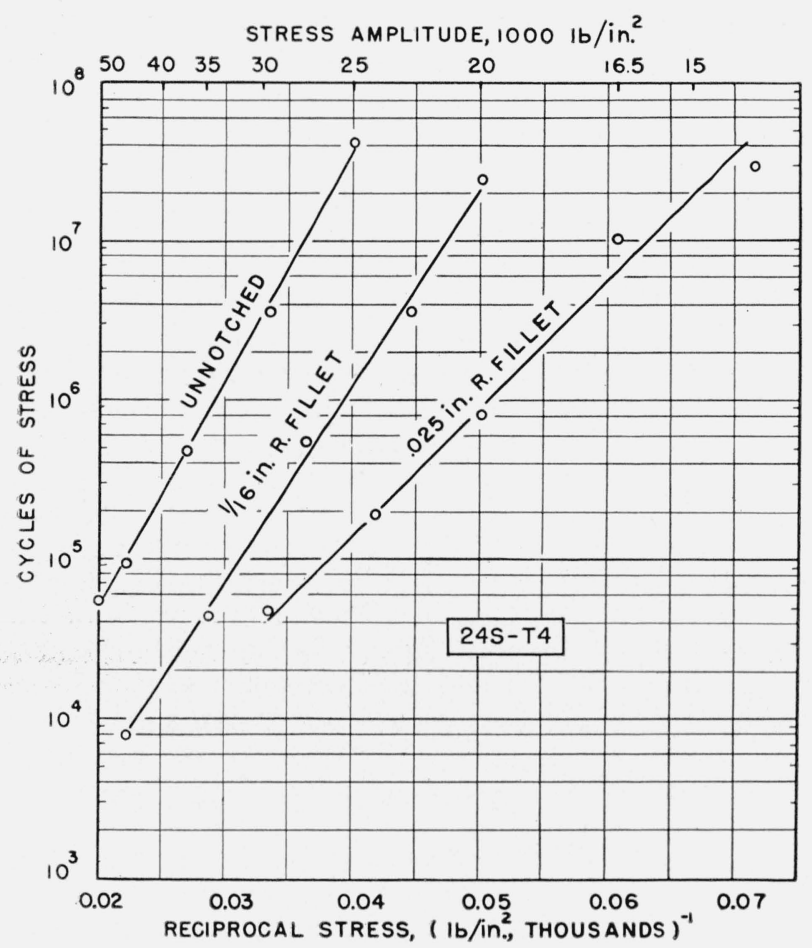

Figure 10. Median $N_{c}$ values for $24 S-T 4$ plotted as a function of reciprocal stress.

STRESS AMPLITUDE, $1000 \mathrm{lb} / \mathrm{in}^{2}$

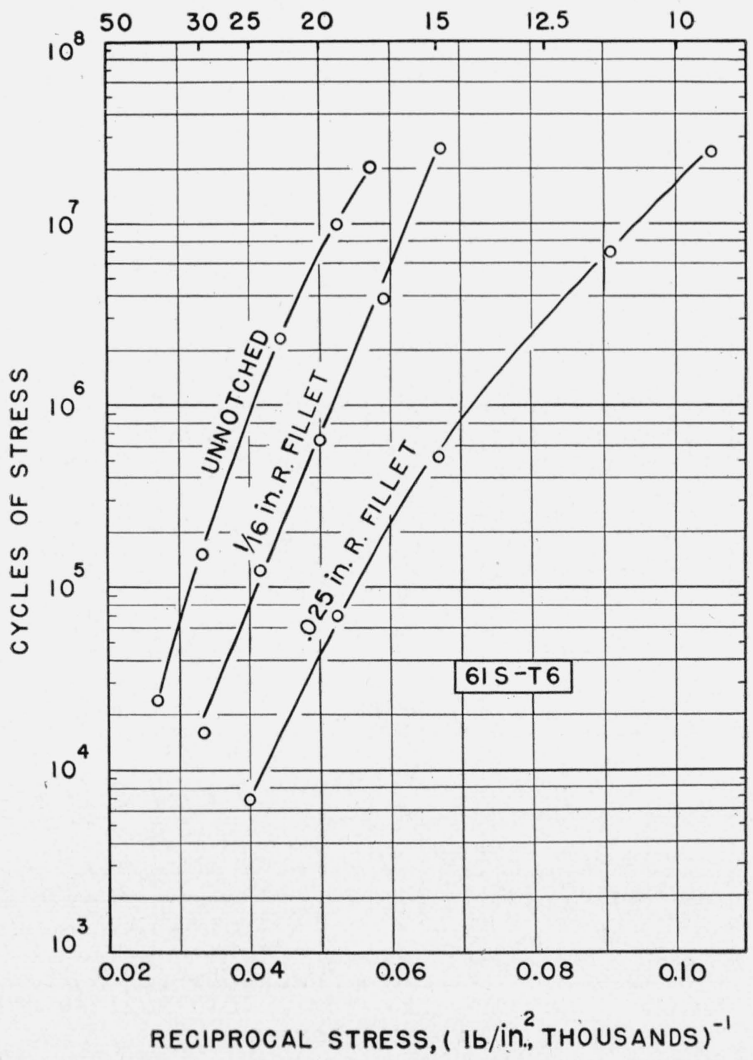

Figure 11. Median $N_{c}$ values of 61S-T6 plotted as a function of reciprocal stress.

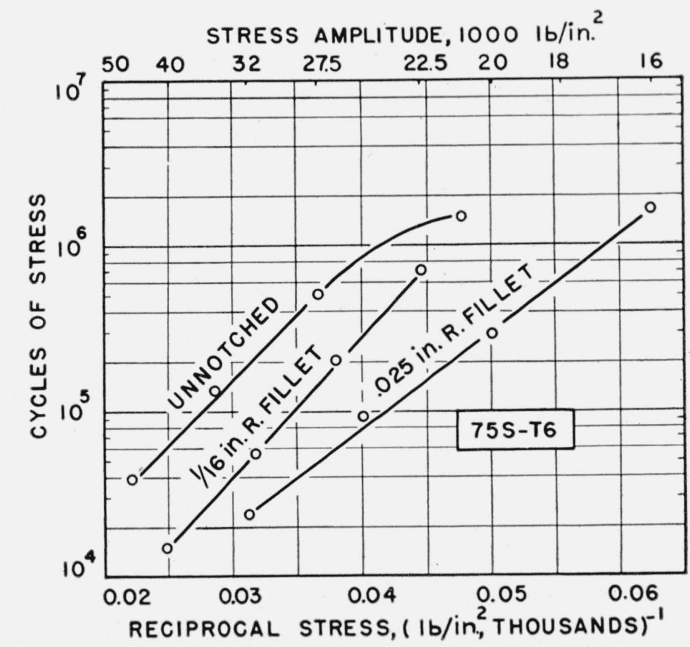

Figure 12. Median $N_{c}$ values for $75 S-T 6$ plotted as a function of reciprocal stress.

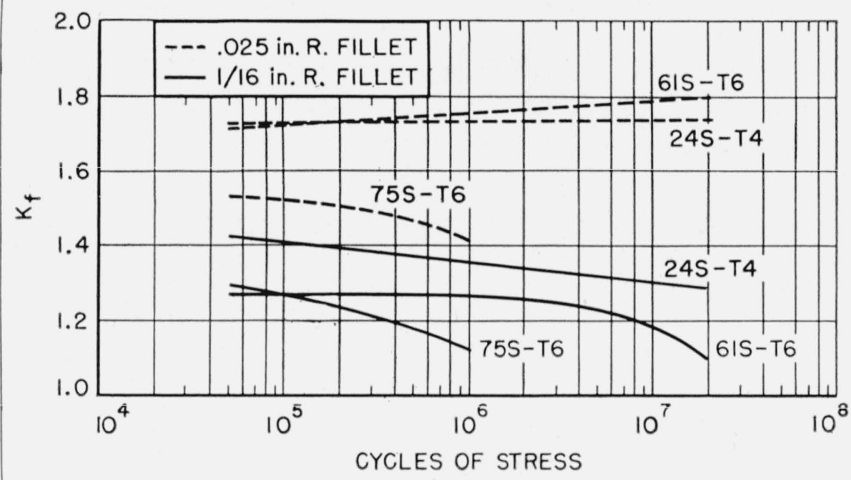

FIgURE 13. Variation of fatigue strength reduction factor $K_{f}$ with $N_{c}$.
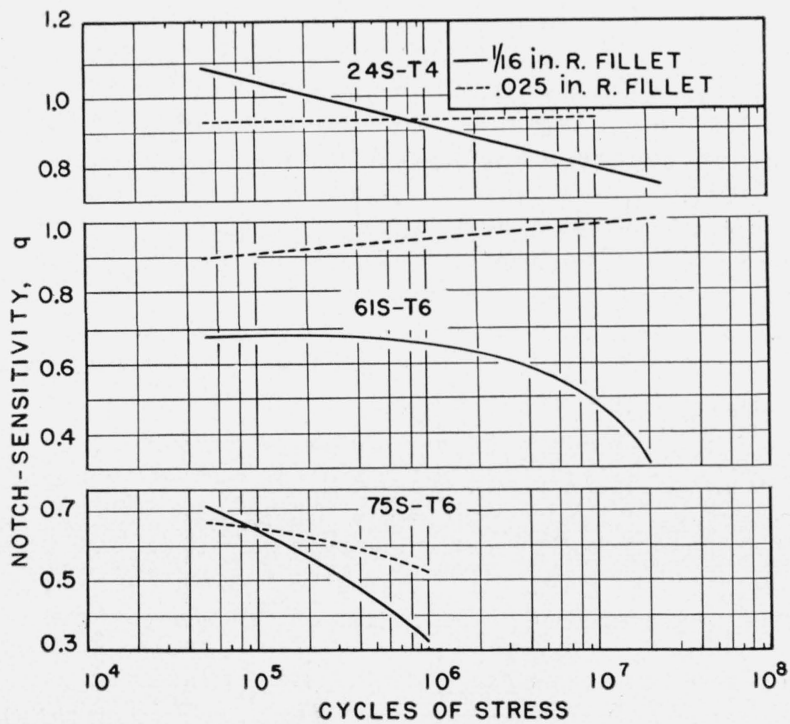

FIGURE 14. Variation of notch sensivitity, $q$, with $N_{c}$. 
The Statistical Engineering Section of the NBS made a more rigorous statistical analysis of these same data and found that after eliminating one extreme value for each of the three materials, they all passed the homogeneity of variance test. That is, the variances at the different stress levels for each metal do not exhibit any more scatter than would be expected by chance in a sequence of estimates of a single variance. This analysis gave the following results regarding the dispersion of all the data for a given material.

\begin{tabular}{|c|c|}
\hline Alloy & $\begin{array}{c}\text { Standard devia- } \\
\text { tion of } \log N_{\mathrm{c}}\end{array}$ \\
\cline { 2 - 2 } 24S-T4 & 0.194 \\
61S-T6 & .123 \\
75S-T6 & .283 \\
\hline
\end{tabular}

As these data were obtained under essentially identical conditions, the figures above should give a fair representation of the relative variability of the fatigue properties of the three alloys.

It has been suggested [12] that fatigue data are more nearly normally distributed with regard to log $N$ than with regard to $N$, and that consequently the mean of $\log N$ is the most desirable representation of a group of data. Several groups of the results obtained in the present investigation were analyzed in this way, but it did not appear to give significantly different results from the median. As this method of analysis did not permit the use of the results from specimens that broke away from the fillets, it was abandoned.

An attempt was also made to analyze the data from the filleted specimens by considering each fillet as a separate specimen and treating the data on a "weakest of two" basis. Again, no significant change in the overall results was noted.

It has been pointed out [13] that there should be a correlation between the dispersion of the number of cycles to failure in fatigue tests and the dispersion of the location of the fatigue-crack nucleus relative to the point of maximum stress. It was felt that some information on the latter dispersion would be of value in studying the effect of microstructure on fatigue behavior. Accordingly, the positions of the origins of the cracks, relative to the point of maximum stress, were determined for about two-thirds of the fractured smooth specimens, selected at random. The three materials were compared on the basis of the proportion of cracks starting at points where the stress was less than 98 percent of the maximum, as follows:

\begin{tabular}{|c|c|}
\hline Alloy & $\begin{array}{c}\text { Percentage of } \\
\text { crack origins at } \\
\text { less than 98\% } \\
\text { of } S_{\max }\end{array}$ \\
\hline 24S-T4 & 8 \\
61S-T6 & 6 \\
75S-T6 & 22 \\
\hline
\end{tabular}

It was also noted that no cracks started in $24 \mathrm{~S}$ or $61 \mathrm{~S}$ specimens at points where the stress was less than 96 percent of the maximum, whereas about 10 percent of the $75 \mathrm{~S}$ specimens had cracks starting where the stress was 90 percent or less. Thus the data on location of fracture verify the conclusion that the $75 \mathrm{~S}-\mathrm{T} 6$ is more inhomogeneous than the other alloys as regards resistance to fatigue.

The locations of the fatigue-crack nuclei were also determined on about a quarter of the filleted specimens by measuring, on a toolmakers microscope, the angle between the axis of the specimen and the surface of the fillet at the origin of the crack. The accuracy of this measurement was probably only fair, particularly on the small radius specimens, but the results are thought to be of some value. No significant difference could be noted between the distribution of locations for different materials or for different stress levels. Accordingly, the data for all specimens of a given fillet radius were grouped together, and the resulting distribution curves are shown in figure 15. There appears to be a definite tendency for the cracks to occur at larger angles in the small-radius specimens.

These distribution curves provide a basis for comparing the areas in which the stress is sufficiently high to initiate fracture in the different specimens. The data discussed above showed that for the 24S-T4 and $61 \mathrm{~S}-\mathrm{T} 6$ smooth specimens, about 93 percent of the cracks were initiated at points where the stress was 98 percent of the maximum or greater. These points were in an area extending 0.09 in. each side of the center. Using the curves of figure 15 to determine the arc length in the fillets in which 93 percent of the cracks would be expected to occur, it is possible to compare the "critically stressed area"

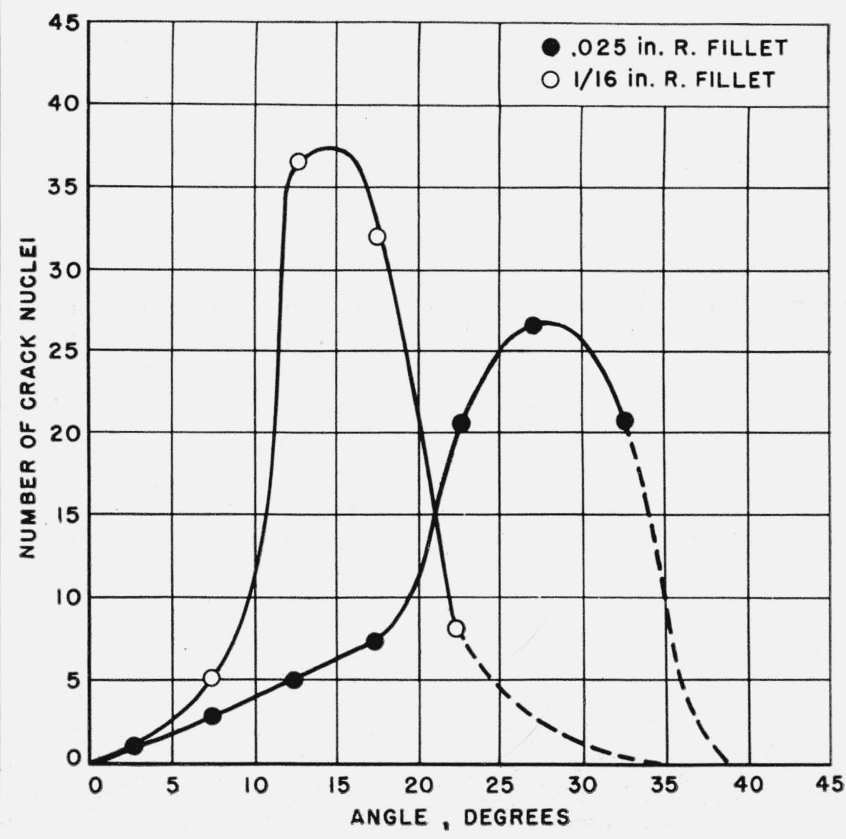

FIGURE 15. Variation in number of crack nuclei with angle between specimen axis and tangent to the surface. 
in the three types of specimens. The ratios obtained are as follows:

\begin{tabular}{|c|c|}
\hline Specimen type & $\begin{array}{c}\text { Relative critically } \\
\text { stressed area }\end{array}$ \\
\hline Smooth & 100 \\
$1 / 16$-in. radius & 22 \\
0.025 -in. radius & 14 \\
\hline
\end{tabular}

On the same relative basis, the area of the straight section of the filleted specimens is 550 .

Two decided differences will be noted between the trends of the notch-sensitivity data obtained in this work and most of those previously reported in the literature. First, the value of $q$ for some of the test conditions is close to unity, while many of the previously available data show lower values. Second, more than half of the curves in figure 14 show that $q$ decreases with increasing number of cycles to failure, which is opposite to that often found.

The explanation for the first discrepancy probably lies in differences in the methods of specimen preparation mentioned in the introduction. If the methods used were such that the surface of notched specimens was more severely cold-worked than that of the unnotched specimen, the resultant value of $q$ would be lower than the value obtained from specimens having comparable surface preparation. The second discrepancy, that in the variation of $q$ with stress level, can be explained in part on the basis of the divergence between the number of cycles to fracture and the number of cycles to initiate a crack. The curves of figures 7 to 9 show that in general the proportion of the life required for the crack to grow to fracture increases with the stress amplitude and with the sharpness of the notch. Therefore, in tests run to fracture there will be less difference in fatigue strength between smooth and notched specimens than in tests based on $N_{c}$, particularly at high stress levels. In order to get an idea of the magnitude of this effect, the notch sensitivity was computed on the basis of $N_{f}$, and it was found that for the sharper notch, $q$ did increase with increasing number of cycles to failure in the tests of 24S-T4 and 61S-T6. However, for the mild notch the reverse was true. The values for 75S-T6 specimens for both notches were approximately constant at a notch sensitivity of about 0.5 .

In attempting to explain the behavior shown on figure 14, one naturally starts with the observation that 3 of the 6 curves lie close to a $q$ value of unity over most of their length. It is convenient, therefore to assume that this is the normal expectancy, and that it is the deviations from this behavior that require explanation. It should be noted that the values of $K_{t}$ used in the computation of $q$ were based on the maximum principal stress in the fillet, so the above assumption is equivalent to saying that the normal criterion for failure in fatigue is the maximum principal stress.
The notch sensitivity of the 75S-T6 alloy was well below that of the other materials in both types of specimens. In considering the possible reasons for this, certain other differences between the behavior of this alloy and the lower strength ones appeared significant. These were:

1. The ratio of the fatigue to static strengths was lower in 75S-T6, as shown below. (The fatigue strengths used are those of the unnotched specimens at $10^{6}$ cycles.)

\begin{tabular}{|c|c|c|}
\hline \multirow{2}{*}{ Alloy } & $\frac{\text { Fatigue strength }}{\text { Yield strength }}$ & $\frac{\text { Fatigue strength }}{\text { Tensile strength }}$ \\
\hline 24S-T4 & 0.60 & \\
61S-T6 & .60 & 0.46 \\
75S-T6 & .32 & .50 \\
& & .27 \\
\hline
\end{tabular}

2. As mentioned above, some of the $75 \mathrm{~S}$ specimens with the $1 / 16$-in.-radius fillets broke in the straight section rather than at the fillet.

3. The dispersion of $N_{c}$ values for the smooth specimens was greater in this alloy.

4. Difficulty was experienced in polishing the 4-in.radius specimens, in that small pits were sometimes found after the standard polishing procedure. Also some specimens that appeared satisfactory after polishing were found to have pits at the origin of the fatigue crack.

Because it appeared that the above differences could be explained by the presence of a relatively few weak or brittle particles randomly distributed in the $75 \mathrm{~S}$ alloy, an attempt was made to observe the microstructures at the origins of the fatigue cracks in this alloy. Several specimens were sectioned transversely and repeatedly ground and polished to permit examination through these regions of origin. One specimen, which was polished with diamond abrasive, contained a particle of the chromium segregate very near the origin of the fatigue crack, as shown in figure 16 . This indicates that the segregate particles, if they occur at the surface, may break out, leaving pits that would serve as stress raisers.

On the basis of these observations, a qualitative explanation of the behavior of $75 \mathrm{~S}-\mathrm{T} 6$ may be proposed; assume that the specimen is composed of a large number of unit volumes that are identical except in the orientation of the direction of greatest strength in the volume relative to the applied stress. The stress required to start a fatigue crack in a given volume then would depend only on this orientation, and in a homogeneous material the distribution of the fatigue strengths of the individual volumes for a given stress direction would have a sharp cutoff, something like that shown in figure 17, and there would be no volumes whose strength was less than some minimum value, $S_{0}$. In a smooth specimen a 


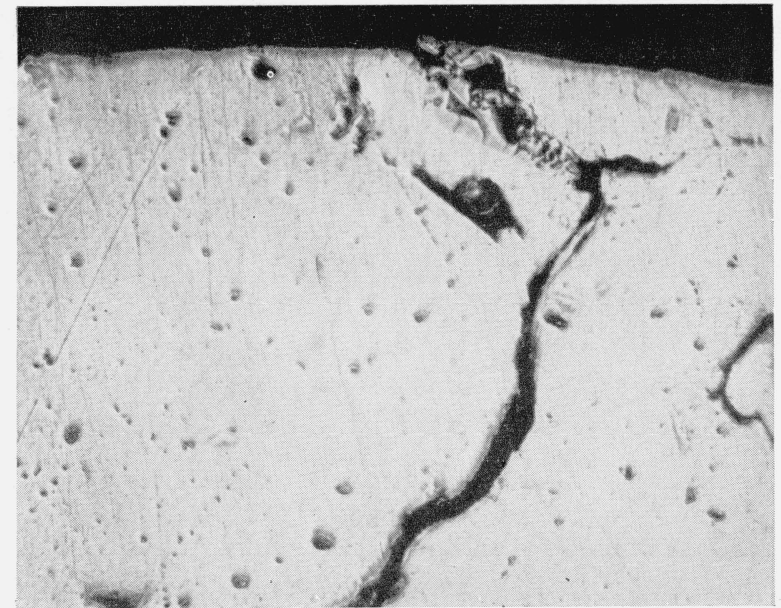

Figure 16. Segregate particle associated with a fatigue crack very near its origin in a specimen of 75S-T6.

Unetched, $\times 250$.

large number of unit volumes are subjected to a high stress. If this number is $M_{s}$, then the strength of the weakest volume in the specimen would be expected to be that represented by a stress value $\left(S_{s}\right.$ in fig. $17, \mathrm{~A})$ which would cut off $1 / M_{s}$ of the area under the curve. In a notched specimen the number of unit volımes to which high stress is applied is smaller, $M_{t}$, and the expected fatigue strength would cut off $1 / M_{t}$ of the area ( $S_{t}$ in fig. 17, A). The nominal fatigue strength of the notched specimen is equal to $S_{t}$ divided by the theoretical stressconcentration factor, $K_{t}$. The fatigue strength reduction factor would be given by $K_{f}=\left(S_{s} K_{t}\right) / S_{t}$, and as $S_{s}$ and $S_{t}$ are close together, it would be expected that $K_{f}$ would be nearly as large as $K_{t}$.

In a material having internal stress raisers, one would no longer expect a simple distribution of strengths. Each volume adjacent to one of these stress raisers would have its effective strength decreased, so these volumes would represent a second population, whose strength distribution is shown schematically by the lower curve in figure $17, \mathrm{~B}$. The resultant total distribution would have a much longer tail than that of a homogeneous material. If we determine $S_{s}$ and $S_{t}$ for this distribution as we did for the first case, the difference between them is much greater than before, so that the strength-reduction factor would be smaller than that of the homogeneous material.

This qualitative discussion is, of course, oversimplified, but similar considerations can be used to explain the fact that only 75S-T6 filleted specimens broke in the straight section, where the stress is only 71 percent of the maximum in the fillet. The tail of the inhomogeneous distribution apparently extends far enough down to intercept a stress value 71 percent of $S_{t}$, but that of the homogeneous distribution does not.

The suggested explanation of the observed fatigue characteristics of $75 \mathrm{~S}-\mathrm{T} 6$ is obviously not the only

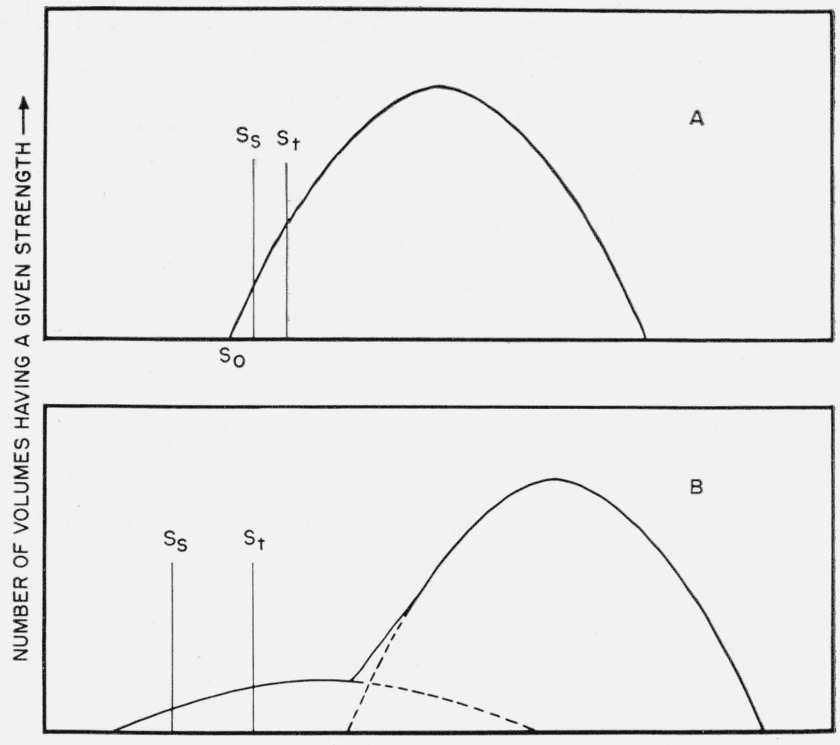

FATIGUE STRENGTH OF A UNIT VOLUME $\longrightarrow$

Figure 17. Hypothetical distribution of the strengths of unit volumes of a homogeneous material $(A)$ and one having internal defects $(\dot{B})$.

possible one. $^{2}$ It appears to be the simplest hypothesis on which to base further experiments, and is offered with that in mind.

The other curve in figure 14 which was not close to unity was that for $61 \mathrm{~S}-\mathrm{T} 6$ in the $1 / 16$-in.-radius specimen. No cause for this anomaly was apparent, but the effect of grain size has not been considered, and this is reported to have an effect on notch sensitivity [14].

An interesting characteristic of the data from all materials is noted if the $K_{f}$ values for the two filleted specimens are compared; the values in the table below are the ratios of the strength-reduction factors for the $1 / 16$-in.-radius specimens to those for the 0.025 -in.-radius specimens.

\begin{tabular}{|c|c|c|c|}
\hline \multirow{2}{*}{ Alloy } & \multicolumn{3}{|c|}{$\begin{array}{c}K_{f 1} / K_{f 2} \text { at the indicated } \\
\text { number of cycles, } N_{c}\end{array}$} \\
\hline & $10^{5}$ & $10^{6}$ & $10^{7}$ \\
\hline $\begin{array}{l}24 \mathrm{~S}-\mathrm{T} 4 \ldots \ldots \\
61 \mathrm{~S}-\mathrm{T} 6 \ldots \ldots \\
75 \mathrm{~S}-\mathrm{T} 6 \ldots \ldots\end{array}$ & $\begin{array}{r}0.82 \\
.75 \\
.83\end{array}$ & $\begin{array}{r}0.77 \\
.73 \\
.79\end{array}$ & $\begin{array}{r}0.75 \\
.66 \\
-\end{array}$ \\
\hline
\end{tabular}

Again, no adequate explanation for the decrease of the ratio with increase in $N_{c}$ can be offered, but the trend is surprisingly consistent.

2 Information has been received that the 75S-T6 cold-finished drawn rod used in this investigation was from a lot produced by an ingot practice that differed from that of the other alloys. This special practice was used for only a short period at the plant that produced this rod. 


\section{Summary}

The notch sensitivities of three aluminum alloys, 24S-T4, 61S-T6, and 75S-T6, for two different notches were evaluated on the basis of the number of cycles to initiate a fatigue crack in a rotatingbeam test. The values for $61 \mathrm{~S}-\mathrm{T} 6$ in the sharp notch and for $24 \mathrm{~S}-\mathrm{T} 4$ were close to unity, indicating that in these cases the maximum stress was the criterion for failure. $75 \mathrm{~S}-\mathrm{T} 6$ showed low values of notch sensitivity, and it is suggested that this may be due to inhomogeneity of the alloy, which would be expected to lower the fatigue strength of smooth specimens more than that of notched specimens.

The dispersion of the data for unnotched specimens was the smallest for $61 \mathrm{~S}-\mathrm{T} 6$ and greatest for $75 \mathrm{~S}-\mathrm{T} 6$.

The proportion of the total life required for a fatigue crack to grow to fracture increased with increasing stress and with increasing notch severity.

The experimental work during the early part of this investigation was conducted by James L. Baker.

\section{References}

[1] R. L. Templin, F. M. Howell, and E. C. Hartmann, Effect of grain direction on fatigue properties of aluminum alloys, Product Eng. (July 1950).

[2] Paul Kuhn and Herbert F. Hardrath, An engineering method for estimating notch-size effect in fatigue tests on steel, NACA Tech. Note 2805 (October 1952).
[3] H. Neuber, Theory of notch stress-principles for exact stress calculation (J. W. Edwards Brothers, Inc., Ann Arbor, Mich., 1946).

[4] C. S. Yen and T. J. Dolan, A critical review of criteria for notch sensitivity in fatigue of metal, ONR Progress Report 13, Project NR-031-005 (Engineering Experiment Station, Univ. of Illinois, 1949).

[5] R. E. Peterson, Design factors for strength calculations for stress concentration cases, Scientific Paper 1540, p. 27 (Westinghouse Research Laboratories, East Pittsburgh, Pa., Oct. 1950).

[6] J. A. Bennett, A study of the damaging effect of fatigue stressing on SAE X4130 steel, J. Research NBS 3\%, 133 (1946) RP1733.

[7] Manual on fatigue testing, Am. Soc. Testing Materials, STP No. 91 (1949).

[8] F. Keller, Metallography of Alcoa $75 \mathrm{~S}$ alloy, Iron Age (Oct. 4, 1945)

[9] J. A. Bennett, Early detection of cracks resulting from fatigue stressing, NACA Bul. 4I, 15 (Sept. 1944).

[10] J. A. Bennett and James L. Baker, Effect of prior static and dynamic stresses on the fatigue strength of aluminum alloys, J. Research NBS 45, 455 (1950; RP2157.

[11] Symposium on fatigue with emphasis on statistical approach, Am. II, Soc. Testing Materials, STP 137 (1953).

[12] G. M. Sinclair and T. J. Dolan, Effect of stress amplitude on statistical variability in fatigue life of $75 \mathrm{~S}-\mathrm{T} 6$ aluminum alloy, Trans. ASME (July 1953).

[13] F. A. McClintock (unpublished report).

[14] R. W. Karry and T. J. Dolan, Influence of grain size on fatigue notch sensitivity, (Office of Naval Research, U. S. Navy, June 1952), ASTM Preprint 72 (1953).

Washington, November 5, 1953. 